\begin{abstract}
"Mircea cel Batran" Naval Academy Scientific Bulletin, Volume XX - 2017 - Issue 2
The journal is indexed in: PROQUEST / DOAJ / Crossref / EBSCOhost/ INDEX COPERNICUS/ OAJI / DRJI I JOURNAL INDEX / I2OR / SCIENCE LIBRARY INDEX / Google Scholar / Academic Keys / ROAD Open Access I Academic Resources / Scientific Indexing Services / SCIPIOI JIFACTOR
\end{abstract}

\title{
SAILING SHIP "MIRCEA" SQUAT CALCULATION USING CFD SIMULATION IN SHALLOW WATERS
}

\author{
Petru Sergiu ȘERBAN ${ }^{1}$ \\ ${ }^{1}$ PhD student instr. eng., Department of Navigation and Naval Transport, "Mircea cel Bătrân” Naval \\ Academy, Constanța, Romania, sergiu.serban@anmb.ro
}

\begin{abstract}
Computational Fluid Dynamics (CFD) is the most recent approach for the evaluation of hydrodynamic parameters of ships and has the advantage of low cost and short time for creating a computerized simulation as opposed to experiments on ship models in towing tanks. The paper aims to follow the process and selection of appropriate methods for geometric and mathematical modelling, as well as preliminary creation of CFD simulation with ANSYS CFX. The hull of sailing ship MIRCEA waS geometrically shaped, after which a shallow fluid domain was defined to study depth effects on the body. These effects mainly relate to variations of pressure, speeds and forces on the hull, but also to ship squat, which was calculated using CFD results.
\end{abstract}

Keywords: CFD simulation, shallow water, ship squat, mesh sensitivity

\section{INTRODUCTION}

The evaluation of hydrodynamic parameters of ships began to gain momentum with the appearance of mechanically propelled ships in the nineteenth century. The most recent approach is the Computational Fluid Dynamics or CFD numerical method, which is the computational technology for analyzing systems that include fluid flow, heat transfer and associated phenomena through computer-based simulation methods [1].

The equations that define the dynamics of fluids are the basic laws of physics, such as the conservation of mass, moment and energy. Thus, CFD methods intend to realistically model the environment and various bodies interacting with it by virtual means and to predict their behaviour under different conditions. In other words, CFD provides researchers and engineers with the ability to perform numerical experiments in a virtual lab.

The advantage of CFD simulations is the low cost and short time for creating a computerized simulation as opposed to model experiments. The disadvantage lies in the variety of mathematical methods and turbulent flow models, leading to general mistrust over their accuracy and reliability. This introduces a certain conservatism and restraint in using these methods and replacing experiments. Therefore, many comparative studies have emerged between the results of CFD simulations and the results of model tests, as well as comparisons between different models of turbulence.

The study presented in this paper follows the process and selection of appropriate methods for geometric modelling, mathematical modelling and preliminary creation of CFD simulation with the ANSYS CFX program, which uses the 3D solver based on the Finite Volume Method.

Having the body plan of sailing ship MIRCEA, the hull was geometrically shaped up to the $7 \mathrm{~m}$ waterline, after which the fluid domain was defined to study depth effects on the body. These effects mainly relate to variations of pressure, speeds, forces and moments on the hull.

\section{GEOMETRY MODELING}

The ratio between depth of water $h$ and draft $T$ allows simulation of the shallow water influence on the hydrodynamic parameters of the vessel, such as drag or drift. The domain must be large enough to prevent the influence of flow at its limits, but the dimensions of the domain are limited by computer performance, so a compromise is required.

Tests in towing tanks can be replaced by CFD techniques with the advantage that they can be applied directly to the prototype. The first step of CFD simulations is to prepare the CAD geometry of the hull. Hull characteristics are presented in table 1 . The final 3D shape of the MIRCEA sailing ship hull used for analysis is shown in figure 2 .

Table 1. Hull geometry parameters [6]

\begin{tabular}{|l|c|c|}
\hline Water line length & $L_{W L}[\mathrm{~m}]$ & 62.061 \\
\hline Water line breadth & $B_{W L}[\mathrm{~m}]$ & 12.00 \\
\hline Height & $D[\mathrm{~m}]$ & 7.00 \\
\hline Draft & $T[\mathrm{~m}]$ & 5.35 \\
\hline Block coefficient & $C_{B}$ & 0.486 \\
\hline
\end{tabular}

The environment in which the ship is moving is known as the domain. A largely enough domain has been created to avoid that its boundaries affect the flow along the hull. The dimensions of the domain (length, width, depth) around the ship are shown in figure 1 and are expressed in terms of waterline hull length, $L_{W L}$. These dimensions were adopted according to the guidelines of the International Towing Tank Conference (ITTC). The simulations were performed for a depth of $\mathrm{h} / \mathrm{T}$ $=1.5$ and at speeds of 2, 4, 6 and 8 knots. 
"Mircea cel Batran" Naval Academy Scientific Bulletin, Volume XX - 2017 - Issue 2

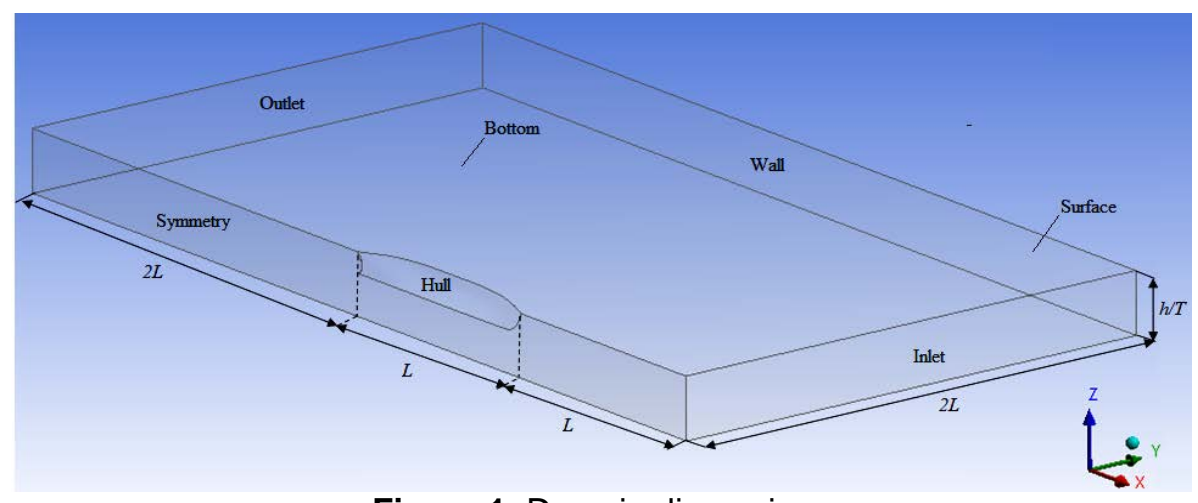

Figure 1. Domain dimensions

The construction of the hull implied the definition of points in the $O X Y Z$ coordinate system with the $X$-axis facing towards the bow, the positive $Y$-axis towards portside and the positive $Z$-axis upwards. Thus, the origin of the coordinate system was considered to be on rib number 0 , in longitudinal plane and on the base line.

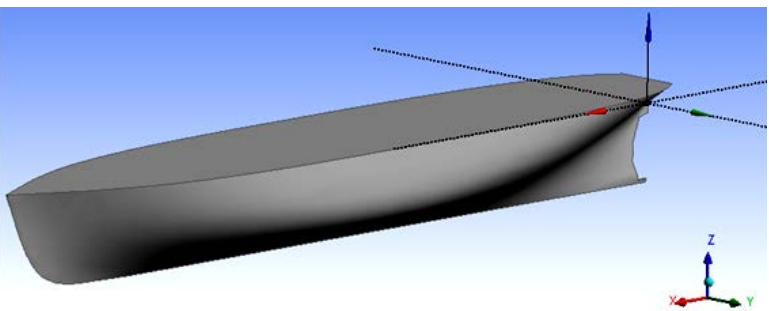

Figure 2. Hull geometry

Stages of hull's geometry construction were as follows:

1. Creating 3D defined curves using coordinate points;

2. Generate a surface joining these curves with the Skin/Loft function;

3. Mirror the surface along $X Z$ plane to generate the starboard, using the Mirror function;

4. Generating a flat surface at the $7 \mathrm{~m}$ draft to close the body;

5. Create a new coordinate system translated on the $Z$ axis to $-5.35 \mathrm{~m}$, to move the body to this elevation so as to obtain the immersed body at the considered draft (fig. 2);

6. Enrol the hull using the Enclosure function in a rectangular body that extends a ship's length from the bow, two lengths to the aft, two lengths in each board, and down from the baseline with $2.675 \mathrm{~m}$; value which corresponds to the considered $h / T$ depth ratio<

7. Extract the ship's body from the domain using the Boolean - Subtract function;

8. Cutting the ship's body to the waterline plane and erasing the emerged part;

9. Cutting the domain along the $O X Z$ plane, using the Symmetry function;
10. Create domain faces using the Named Selection function as: Inlet, Outlet, Surface, Bottom, Wall, Hull and Symmetry (fig. 1).

\section{COMPUTATIONAL DOMAIN MESHING}

The division of the computational domain into a number of cells is called mesh. Particular attention must be paid to meshing, because a poor quality mash has a negative effect on the solution's convergence and confidence in the calculated results [6].

To analyze the flow numerically, the physical domain of fluid is discredited into cells. Flow variables are associated with each cell (element) in the grid. This model uses the finite element method with the second-order meshing. Compared to first-order meshing, it provides greater grid convergence and greater meshing accuracy. Figure 3 shows the cells grid of the fluid domain in the studied case.

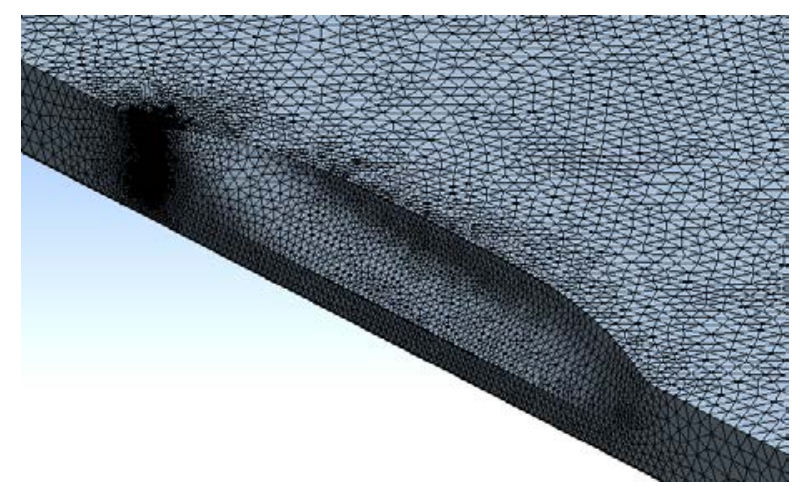

Figure 3. Domain mesh

In order to observe the flow phenomenon in simulations, the density of the cell grid was more concentrated in certain regions of the domain. In this respect, a fine mesh on the surface of the hull was used and cell layers were created along it to solve the flow in the boundary layer. The cell layers were constructed such that the total thickness corresponded to the estimated thickness of the boundary layer and the width of the first cell layer was set to obtain an appropriate value of the $y^{+}$parameter. 


\begin{abstract}
"Mircea cel Batran" Naval Academy Scientific Bulletin, Volume XX - 2017 - Issue 2
The journal is indexed in: PROQUEST / DOAJ / Crossref / EBSCOhost/ INDEX COPERNICUS/ OAJI / DRJI I JOURNAL INDEX I I2OR / SCIENCE LIBRARY INDEX / Google Scholar / Academic Keys / ROAD Open Access I Academic Resources / Scientific Indexing Services / SCIPIO/ JIFACTOR
\end{abstract}

Generation of the fluid domain mesh was done in three steps:

1. A free mesh on the surfaces of the fluid domain had been created to automatically determine a suitable number of divisions on each face edge using the Face Meshing function;

2. The grid cell had been refined using the Tetrahedrons Patch Conforming function;

3. On the hull and on the bottom of the domain, cell layers were added using the Inflation function to capture flow in the boundary layer. For the simulated situation, the thickness of the first layer was calculated so that the value of the $y^{+}$ parameter was 60 for both the hull and the bottom. The maximum number of layers was 15 and the growth rate was 1.2.

To measure the quality of the generated mesh, the Skewness and Orthogonal quality functions in Mesh Statistics - Mesh Metric were used, these being the most important methods of determining grid quality. It is generally recommended to maintain a minimum orthogonality greater than 0.15 and a maximum skewness of less than 0.95 . Cells or elements that do not meet these conditions can lead to incorrect simulation results. However, these are general rules and depend on the type of problem solved or the location of these cells. For the simulated case their values are within the boundaries of a good mesh.

\section{MESH SENSITIVITY STUDY}

In order to determine the accuracy of the CFD solution and to maintain a low computational effort, a mesh sensitivity study was conducted. The case $h / T=1.5$ was chosen with ship speed of 8 knots and turbulence model $k-\omega S S T$. The study included the generation of three different meshes, coarse, medium and fine, to determine how the grid quality affects the simulation results. The number of nodes, simulation time and total force acting on the hull in $Z$ direction are presented in table 2. It sums up the main features of the meshes, where it can be noticed that the time of CFD simulations is dependent on the number of nodes considered in the grid.

The mesh is refined in grids as follows: M1 represents the coarse cell grid, M2 the medium and M3 the fine mesh, where the degree of increase in the number of nodes is about 1.3. The variation of total force acting on the ship's hull in $Z$ direction is shown in figure 4.

Table 2. Mesh size, CFD simulation time and $Z$ force for SST model at $h / T=1.5$

\begin{tabular}{|l|c|c|c|}
\hline $\begin{array}{l}\text { Mesh } \\
\text { resolution }\end{array}$ & $\begin{array}{c}\text { Coarse } \\
\text { mesh (M1) }\end{array}$ & $\begin{array}{c}\text { Medium } \\
\text { mesh (M2) }\end{array}$ & $\begin{array}{c}\text { Fine mesh } \\
\text { (M3) }\end{array}$ \\
\hline $\begin{array}{l}\text { Number of } \\
\text { nodes }\end{array}$ & 866835 & 1078354 & 1458185 \\
\hline $\begin{array}{l}\text { CFD } \\
\text { simulation } \\
\text { time }\end{array}$ & $\begin{array}{c}08 \mathrm{hrs} \\
17 \mathrm{mins}\end{array}$ & $\begin{array}{c}14 \mathrm{hrs} \\
53 \mathrm{mins}\end{array}$ & $\begin{array}{c}23 \mathrm{hrs} \\
51 \mathrm{mins}\end{array}$ \\
\hline$Z$ total force & $4.318 \mathrm{e}+05$ & $4.317 \mathrm{e}+05$ & $4.312 \mathrm{e}+05$ \\
\hline
\end{tabular}

DOI: 10.21279/1454-864X-17-12-016

(c) 2017. This work is licensed under the Creative Commons Attribution-Noncommercial-Share Alike 4.0 License.

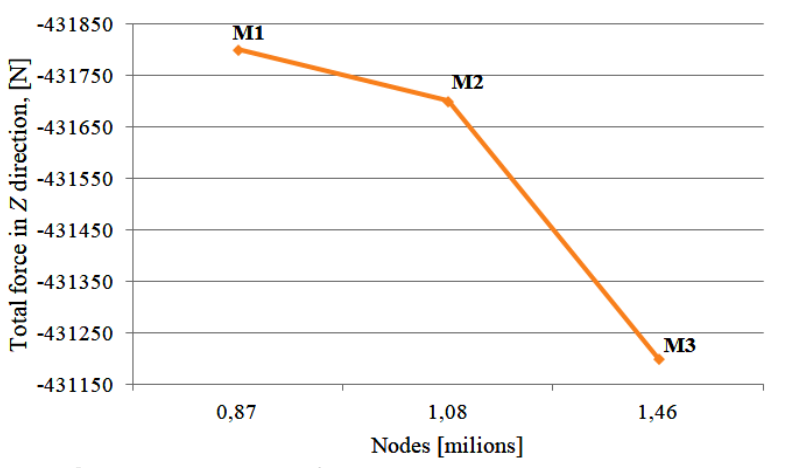

Figure 4. $Z$ total force acting on hull in the 3 studied meshes

The value of the total force acting on the ship's hull in the $Z$ direction becomes smaller as the node grid is refined, resulting in a value of $431200 \mathrm{~N}$ for the M3 mesh. The difference between the values obtained with the $\mathrm{M} 1$ and $\mathrm{M} 2$ meshes is about $1 \%$, but the total time of CFD simulations differs significantly from one grid to another. Due to the small differences and taking into account the calculation time, it was concluded that the M2 medium mesh is the most appropriate and provides good results with a reasonable computational cost.

Conducting a comparative study by refining the mesh is particularly important in the verification step. A finer mesh can lead to more precise results of the model, but consumes more computing resources. The user must strike a balance between the size of the cell grid by which to obtain a sufficiently accurate solution and the consumption of the computing resources. This also depends on the accuracy of the desired results and the applicability of the simulation.

\section{MATHEMATICAL MODEL AND SOLVER}

In the motion of a fluid equations derivation, the exchange rate of the fluid properties $\varphi$ should be known per mass unit and per volume unit. This field is fully described by density $\rho$, velocity $U$, pressure $p$ and viscosity $v$. Using the Euler method, the fluid field $\varphi(x, y, z, t)$ will be investigated assuming that the properties that are relevant are in relation to the fluid's particle position and time. At a given time $t$, the fluid particle is at the coordinate point $(x, y, z)$ and after a time $t+\Delta t$ it moves to another coordinate point $(x+\Delta x, y+\Delta y, z+\Delta z)[2]$.

The rate of change in the properties of a fluid $\varphi$ per volume unit is given by

$$
\frac{\partial \varphi}{\partial t}+\nabla(\rho \vec{U})=0
$$

The shear stresses from the momentum equations can be related to linear deformation rates of the fluid element, which is expressed by velocity components. For an isotropic Newtonian 


\section{"Mircea cel Batran" Naval Academy Scientific Bulletin, Volume XX - 2017 - Issue 2 \\ The journal is indexed in: PROQUEST / DOAJ / Crossref / EBSCOhost/ INDEX COPERNICUS/ OAJI / DRJI I JOURNAL INDEX / I2OR / SCIENCE LIBRARY INDEX / Google Scholar / Academic Keys / ROAD Open Access I Academic Resources / Scientific Indexing Services / SCIPIOI JIFACTOR}

fluid, the relationship between shear stress and deformation rate is given by the following equation,

$$
\left|\begin{array}{lll}
p_{x x} & \tau_{x y} & \tau_{x z} \\
\tau_{y x} & p_{y y} & \tau_{y z} \\
\tau_{z x} & \tau_{z y} & p_{z z}
\end{array}\right|=-\left|\begin{array}{ccc}
p & 0 & 0 \\
0 & p & 0 \\
0 & 0 & p
\end{array}\right|+2 \mu \cdot\left|\begin{array}{ccc}
\varepsilon_{x} & \vartheta_{z} & \vartheta_{y} \\
\vartheta_{z} & \varepsilon_{y} & \vartheta_{x} \\
\vartheta_{y} & \vartheta_{x} & \varepsilon_{z}
\end{array}\right| \text {. (2) }
$$

This is the momentum equations in the most convenient form for finite volume method. In some sources, Navier-Stokes equations are associated with momentum equations and continuity equation system.

The simulation was performed based on RANSE method for incompressible viscous flow, which is derived from averaging Navier-Stokes equations. Mediation leads to a set of partial differential equations called Reynolds averaged Navier-Stokes equations (RANSE) which is the main mean in the CFD arsenal methods used today for calculating turbulent flows [4].

In this paper, viscous flow along the ship's hull is supposed to be incompressible and the numerical problem is described by RANS equations.

Two-equation turbulence models are some of the most common types of turbulence patterns. Models such as $k-\varepsilon$ or $k-\omega$ have become standard models and are often used for various types of engineering problems. The $k-\omega$ model is one of the most common turbulence models, which includes two transport equations that represent the flow turbulence properties. These transport equations are solved for turbulence kinetic energy $k$ and specific dissipation $\omega$.

The $k-\omega$ model has the advantage that it is valid in areas close to walls and also in regions with low turbulence, which means that the transport equations can be used across the entire flow domain. A disadvantage of this model is that the results are sensitive to the choice of boundary conditions and initial conditions.

To use together the advantages of the $k-\varepsilon$ and $k-\omega$ models, Menter (1994) developed the shear stress transport model (SST), combining the two models into one using mixing functions. In this hybrid model, the $k-\omega$ model is used into the boundary layer flow, while the $k-\varepsilon$ model is used in the free flow.

The $k-\omega$ SST showed good performance for many types of complex flows, such as high pressure gradient flow and separate flow, where the $k-\varepsilon$ and $k-\omega$ models yielded significantly different results from the experimental data. The model is recognized for good performance and is the most commonly used turbulence model for naval hydrodynamic simulations [5].

To decide if a solution has reached the desired level of convergence, it is useful to monitor, for each iteration, the residuals of flow variables. Residuals are a measure of the imbalance between the left and right sides of a discreet transport equation. They are the most important measures of convergence because they are directly related to the correct solving of the equations.

The CFX solver uses residual to establish convergence. Normalized residuals are used to automatically shut down the solver when a specified level is reached. To see when convergence is achieved, the user must select the type of residuals, MAX (maximum) or RMS (root mean square), and specify a target value. In CFD simulations, RMS residuals with a target value of $10^{-5}$ were used, which is good convergence and is sufficient for most engineering applications [7].

To establish convergence, besides observing residuals, it is possible to check the mass, moment and energy imbalance in each cell. It is also necessary to monitor whether the important variables of the solution have reached stable values. In naval hydrodynamic simulations, ship resistance, squat and trim are monitored until they oscillate with small amplitude around a stable value.

The limits that define and separate the fluid areas can be of different types and depend on the problem setting and the functions fulfilled by these limits in solution. The most commonly used boundary types are wall, input, output, symmetry, periodic and interface.

The walls are the impenetrable surfaces limiting the fluid. In this study, the no slip condition was used, this being most common in the viscous flow simulations, which causes the fluid to adhere to the wall and move at the same speed as the wall, if it moves.

The inlet and outlet boundaries are the areas through which the fluid enters and exits the computing domain. The appropriate boundary conditions for these surfaces are created to take account of the different processes occurring at the input and output limits. For this study the condition used at the entry of the fluid domain was the velocity inlet, which defines the velocity and the scalar properties of the flow. These conditions are most used for both internal and external flow problems encountered in marine simulations. The condition at the output limit used was the pressure outlet, which sets the static pressure value, being the most suitable for CFD marine simulations. If the location of the output limit is far enough away from the target object of the simulation that induces turbulence in the flow domain, it can be assumed that the outlet pressure is equal to the hydrostatic pressure.

The boundary condition set on the domain bottom was no slip wall. Also, the roughness of the bottom was defined by entering the specific roughness of sand. 
"Mircea cel Batran" Naval Academy Scientific Bulletin, Volume XX - 2017 - Issue 2

The journal is indexed in: PROQUEST / DOAJ / Crossref / EBSCOhost/ INDEX COPERNICUS/ OAJI / DRJI /

JOURNAL INDEX / I2OR / SCIENCE LIBRARY INDEX / Google Scholar / Academic Keys / ROAD Open Access I Academic Resources / Scientific Indexing Services / SCIPIOI JIFACTOR

The boundary condition on the hull was set no slip wall, stationary; at the surface and on the lateral limits of the domain, the free slip wall condition, and on the symmetry plan, the symmetry condition.

Simulations were performed for $h / T=1.5$ and 4 ship speed values. The following assumptions and simplifications were made:

- homogeneous flow of incompressible fluid;

- linear motion with constant speed;

- surface without waves and currents;

- width of the domain equals to four ship lengths to eliminate the wall effect;

- ship is considered to be without the influence of the rudder or the propeller;

- ship is assumed to have no trim;

- surface of the hull is perfectly fine;

- flat bottom without natural disturbances;

- simulation without dynamic mesh;

- due to flow symmetry, calculations were performed for half of the domain;

- geometric modelling of the ship was made on a natural scale;

- fluid flow was carried out in a rectangular area around the hull.

\section{RESULTS AND DISCUSSIONS}

Calculations were performed with the ANSYS CFX solver. The turbulent flow was simulated by solving Reynolds averaged Navier-Stokes equations for incompressible flow. The velocity field is obtained from the moment conservation equations and the pressure field is extracted from the mass conservation condition or the continuity equation converted to a pressure equation. In the case of turbulent flows, additional transport equations for modelling variables are used and solved using the same principles [3].

All the calculations presented were made on the non-annexed body of the MIRCEA sailing ship. The ANSYS CFX solver converts the differential equations defined in the mathematical

model into a set of algebraic equations. By solving these equations, the values for $u, v, w, p, k, \omega$ in the centre of each cell of the domain are obtained. Thus, a number of algebraic equations and unknowns are obtained equal to 6 times the total number of cells in the mesh. This huge set of algebraic equations is solved by an iterative process. The total time allocated to the simulations has been calculated so that a fluid particle passes at least once the entire fluid domain. The time step for each computation was $0.1 \mathrm{~s}$. The calculations were performed with a single iteration each time step.

In the post-processing step, the desired information is extracted from the data set generated by the CFD. Versatile viewing features are an asset of CFD packages, with results being represented in spreadsheets, graphics, or contours. Thus, pressure profiles and forces acting on the ship's body, as well as speed profiles in different sections were determined.

The analysis of the obtained results is done for the $h / T=1.5$ case at all considered speeds, 2 , 4, 6 and 8 knots, respectively, in order to give a picture of the speed influence on hull in shallow water. Table 3 shows the total forces, comprised of pressure forces and viscous forces, acting on the hull in the three directions at all four considered speeds. The resulting force in the $X$ direction represents the ship's resistance, in the $Y$ direction the drift and in the $Z$ direction the vertical hydrodynamic force that causes the ship to sink due to interaction with the bottom.

Graphically, the differences between the total forces on the $Z$ axis at speed change can be seen in figure 5. It decreases from - $26664 \mathrm{~N}$ at 2 knots to $-431700 \mathrm{~N}$, which proves that, in this case $(h / T=1.5)$, the limited under keel clearance of $2,675 \mathrm{~m}$, produces hydrodynamic effects on the hull as the speed of the vessel increases.

Table 3. Total forces acting on hull for $h / T=1.5$

\begin{tabular}{|c|c|r|r|r|}
\hline \multirow{2}{*}{ Speed, $\boldsymbol{V}_{\boldsymbol{K}}$} & \multirow{2}{*}{ Axis } & \multicolumn{3}{|c|}{ Type } \\
\cline { 2 - 5 } & & Pressure Force & Viscous Force & \multicolumn{1}{c|}{ Total Force } \\
\hline \multirow{3}{*}{2 knots } & $X$ & $-1.8896 \mathrm{e}+06$ & $-6.7361 \mathrm{e}+06$ & $-8.6256 \mathrm{e}+03$ \\
\cline { 2 - 5 } & $Y$ & $2.1895 \mathrm{e}+04$ & $1.4989 \mathrm{e}+01$ & $2.1910 \mathrm{e}+04$ \\
\cline { 2 - 5 } & $Z$ & $-2.6659 \mathrm{e}+04$ & $-5.4302 \mathrm{e}+00$ & $-2.6664 \mathrm{e}+04$ \\
\hline \multirow{3}{*}{ knots } & $X$ & $-3.1287 \mathrm{e}+03$ & $-4.7776 \mathrm{e}+03$ & $-7.9063 \mathrm{e}+03$ \\
\cline { 2 - 5 } & $Y$ & $8.8131 \mathrm{e}+04$ & $4.4426 \mathrm{e}+01$ & $8.8176 \mathrm{e}+04$ \\
\cline { 2 - 5 } & $Z$ & $-1.0688 \mathrm{e}+05$ & $-2.8185 \mathrm{e}+01$ & $-1.0691 \mathrm{e}+05$ \\
\hline \multirow{3}{*}{ knots } & $X$ & $-1.5714 \mathrm{e}+03$ & $-5.0237 \mathrm{e}+03$ & $-6.5951 \mathrm{e}+03$ \\
\cline { 2 - 5 } & $Y$ & $1.9800 \mathrm{e}+05$ & $8.8746 \mathrm{e}+01$ & $1.9809 \mathrm{e}+05$ \\
\cline { 2 - 5 } & $Z$ & $-2.4043 \mathrm{e}+05$ & $-3.7657 \mathrm{e}+01$ & $-2.4046 \mathrm{e}+05$ \\
\hline \multirow{3}{*}{ knots } & $X$ & $-2.5288 \mathrm{e}+03$ & $-4.1342 \mathrm{e}+02$ & $-2.9422 \mathrm{e}+03$ \\
\cline { 2 - 5 } & $Y$ & $3.5263 \mathrm{e}+05$ & $2.7119 \mathrm{e}+00$ & $3.5264 \mathrm{e}+05$ \\
\cline { 2 - 5 } & $Z$ & $-4.3170 \mathrm{e}+05$ & $4.4192 \mathrm{e}+00$ & $-4.3170 \mathrm{e}+05$ \\
\hline
\end{tabular}


"Mircea cel Batran" Naval Academy Scientific Bulletin, Volume XX - 2017 - Issue 2

The journal is indexed in: PROQUEST / DOAJ / Crossref / EBSCOhost/ INDEX COPERNICUS/ OAJI / DRJI I JOURNAL INDEX / I2OR / SCIENCE LIBRARY INDEX / Google Scholar / Academic Keys / ROAD Open Access I Academic Resources / Scientific Indexing Services / SCIPIOI JIFACTOR

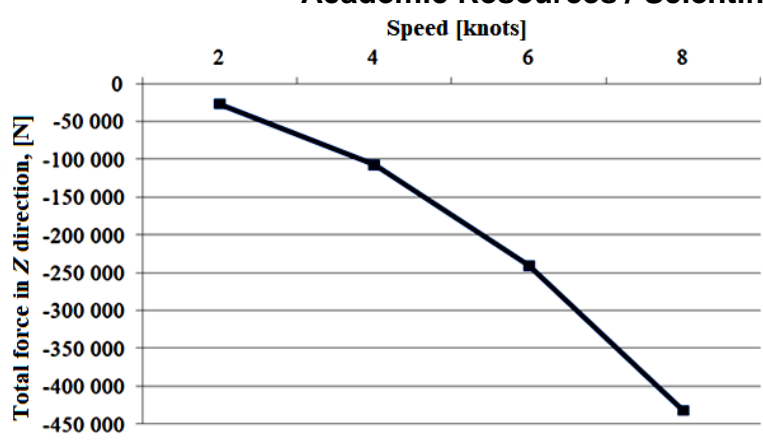

Figure 5. Variation of total force in $Z$ direction at considered speed for $h / T=1.5$

Slight differences can be observed between cases by comparing the contours of these vertical forces with respect to the speed change, which once again emphasizes that hydrodynamic forces acting on the hull change when the vessel speeds up in areas with shallow water. The representation of these forces in the form of contours on the hull can be seen in figure 6 .

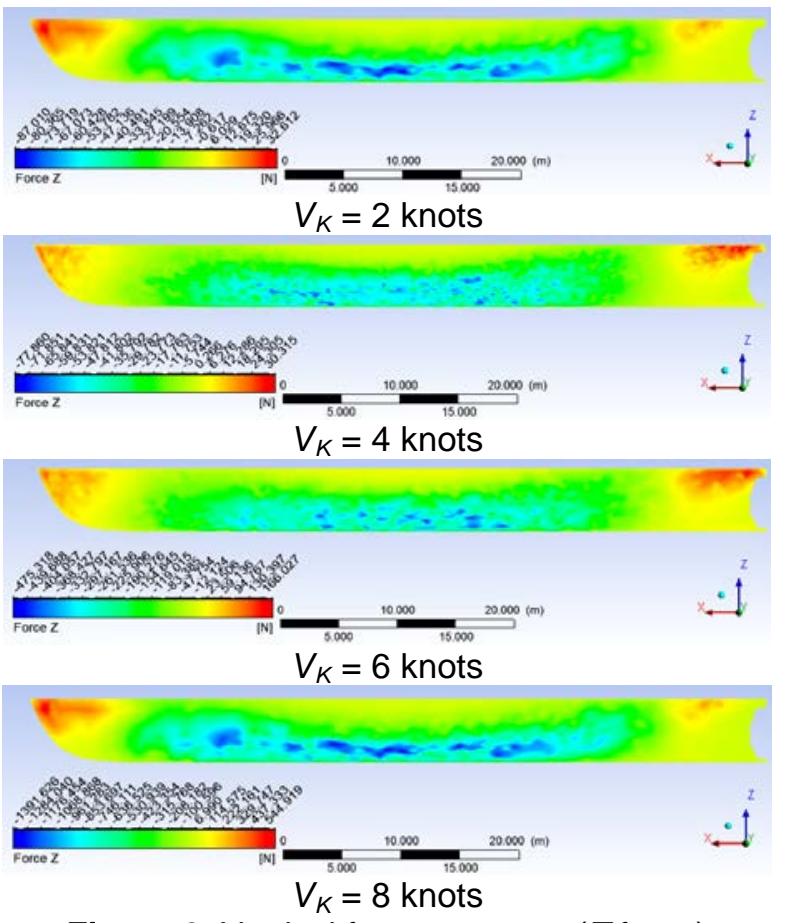

Figure 6. Vertical force contours ( $Z$ force)

The pressure variation on the hull is shown in figure 7 , where it can be seen that its distribution is normal for a ship's body, having a positive pressure bulb in the bow and aft and a negative pressure domain on the bottom of the hull, along the body.

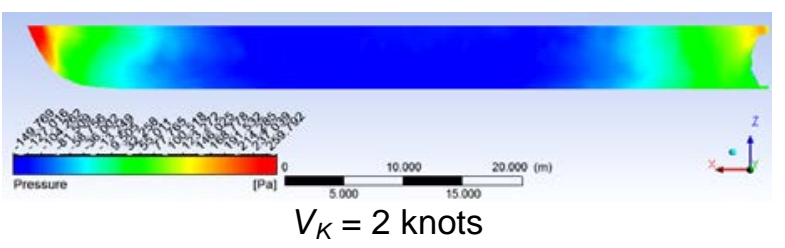

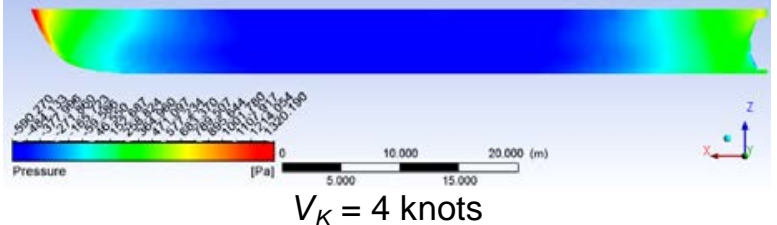
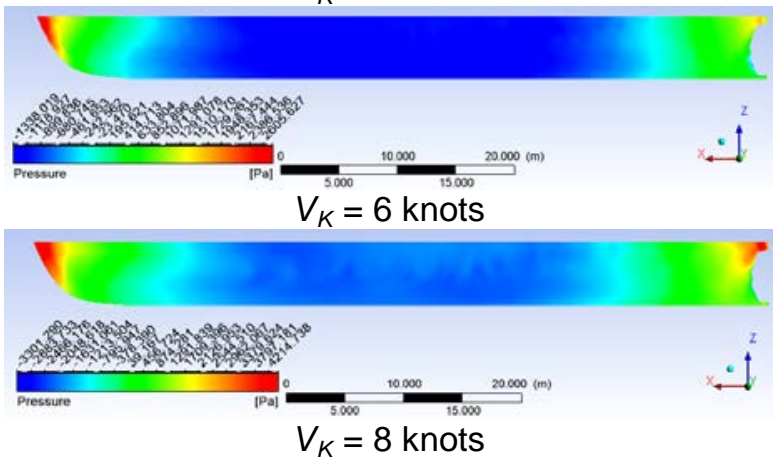

Figure 7. Pressure contours on hull at considered speeds

CFD post-processing enables the variation of the pressure across the keel in the longitudinal plane, which is shown in figure 8 . It can be observed that the maximum pressure at all the speeds is in the bow and the minimum at amidships. By comparing the four situations, one can conclude that a higher ship velocity causes a greater pressure drop, even if the depth is constant. Also, the position of the zero pressure points at both the bow and the aft is approximately the same for all considered speeds.

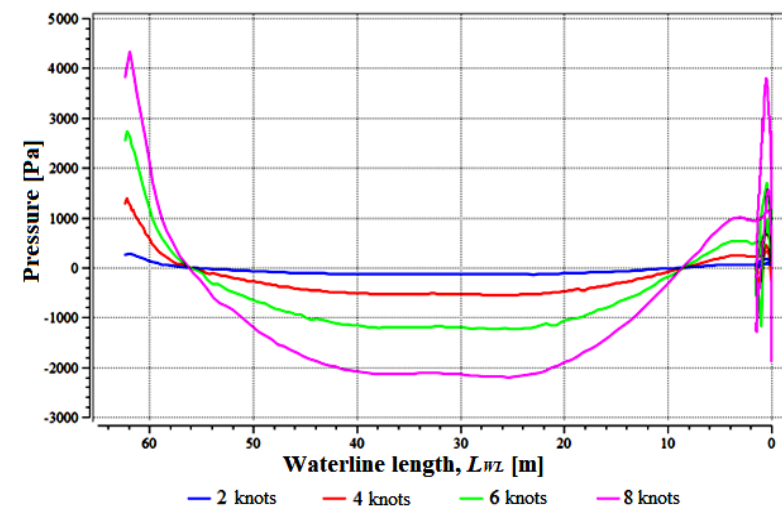

Figure 8. Pressure variation on keel

The velocity variation in the fluid domain along the hull during the simulation is presented in the form of the contours in figure 9. As expected, the potential increase in flow velocity can be observed due to the interaction between the ship's body and the bottom of the domain. In all four cases presented, in the area between the hull and the bottom, the maximum velocity of the fluid is $12.6 \%$ higher than the fluid velocity at the beginning of the simulation. 
"Mircea cel Batran" Naval Academy Scientific Bulletin, Volume XX - 2017 - Issue 2

The journal is indexed in: PROQUEST / DOAJ / Crossref / EBSCOhost/ INDEX COPERNICUS/ OAJI / DRJI I JOURNAL INDEX / I2OR / SCIENCE LIBRARY INDEX / Google Scholar / Academic Keys / ROAD Open Access I Academic Resources / Scientific Indexing Services / SCIPIOI JIFACTOR

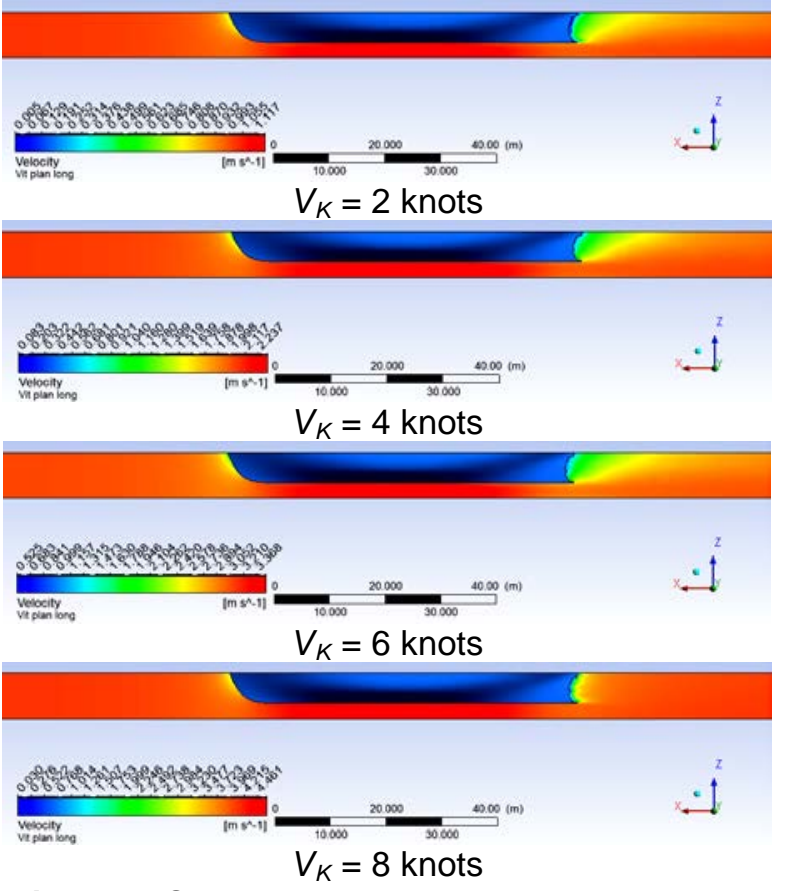

Figure 9. Speed contours in longitudinal plane at considered speeds

To verify if the method used is good and the solution converged, it was checked if the total mass of fluid at inlet is equal to the mass at outlet. In the analyzed case $(h / T=1.5)$, for each speed, this is observed in the Mass Flow column, in table 4. The numerical convergence adopted for these calculations was the criterion of reducing the maximum difference between consecutive iterations of the three components of velocity and pressure below $10^{-5}$.

Table 4. Mass flow for $h / T=1.5$

\begin{tabular}{|c|c|r|}
\hline Speed & Location & \multicolumn{1}{c|}{ Mass Flow } \\
\hline \multirow{2}{*}{$V_{K}=2$ knots } & inlet & $1.0710 \mathrm{e}+06$ \\
\cline { 2 - 3 } & outlet & $-1.0710 \mathrm{e}+06$ \\
\hline \multirow{2}{*}{$V_{K}=4$ knots } & inlet & $2.1420 \mathrm{e}+06$ \\
\cline { 2 - 3 } & outlet & $-2.1420 \mathrm{e}+06$ \\
\hline \multirow{2}{*}{$V_{K}=6$ knots } & inlet & $3.2131 \mathrm{e}+06$ \\
\cline { 2 - 3 } & outlet & $-3.2131 \mathrm{e}+06$ \\
\hline \multirow{2}{*}{$V_{K}=8$ knots } & inlet & $4.2841 \mathrm{e}+06$ \\
\cline { 2 - 3 } & outlet & $-4.2841 \mathrm{e}+06$ \\
\hline
\end{tabular}

As far as concerning the validation, there are currently no experimental data conducted on board sailing ship "MIRCEA" for validation of the simulation results, but in the literature the method used for the simulations is confirmed by simulations performed on standard hulls, such as KCS or KVLCC2 Moeri tanker, already validated with experimental data.

Vertical hydrodynamic forces, calculated with ANSYS CFX, were used for calculation of ship squat. They represent the sum of the static and dynamic buoyancy force, the latter varying according to the hydrodynamic pressure generated by the hull motion over the bottom of the domain. The values of total buoyancy force and its variation due to ship speed were presented in figure 5 .

In $h / T=1.5$ case the speeds for which the simulations were performed were 2, 4, 6 and 8 knots. The maximum vertical hydrodynamic force is $-26664 \mathrm{~N}$ at 2 knots and the minimum value is - $431700 \mathrm{~N}$ at 8 knots. The force variation is normal and proportional to the speed increase.

In conclusion, it can be argued that when increasing the ship's speed in shallow water, the vertical hydrodynamic force decreases, having higher negative values, indicating a strong interaction between the hull and the bottom of the domain.

Ship squat can be calculated using the total buoyancy force obtained in the simulations, with the following formula

$$
\text { Squat }=Z l \rho \cdot g \cdot A_{w l},
$$

where $\rho$ is water density, $Z$ - total buoyancy force and $A_{w l}-$ waterline plane area.

For the studied case, the area $A_{w l}$ is 565.74 $\mathrm{m}^{2}$ at $5.35 \mathrm{~m}$ draft. Therefore, the squat values for the hull of sailing ship MIRCEA presented in table 5 were obtained. Graphically, the variation of squat due to speed is shown in figure 10.

Table 5. Ship squat values for $h / T=1.5$

\begin{tabular}{|c|c|}
\hline Speed, $\boldsymbol{V}_{\boldsymbol{K}}$ & Squat $[\mathrm{m}]$ \\
\hline 2 knots & -0.004821 \\
\hline 4 knots & -0.019329 \\
\hline 6 knots & -0.043475 \\
\hline 8 knots & -0.078051 \\
\hline
\end{tabular}

Of all the simulated conditions, the highest value of squat is obtained at the speed of 8 knots, $0.078051 \mathrm{~m}$, which is normal that for a shallow depth and at highest tested speed the highest value of the squat is obtained.

It is noted that the variation of squat is dependent on depth and speed. Thus, a smaller under keel clearance and a higher speed results in a more pronounced squat and the increase of ship's draft. It should be emphasized, however, that the values obtained from the CFD simulations are in the order of centimetres, values which are in accordance with ship dimensions and considered speeds, but which could be difficult to see in reality. 
"Mircea cel Batran" Naval Academy Scientific Bulletin, Volume XX - 2017 - Issue 2

The journal is indexed in: PROQUEST / DOAJ / Crossref / EBSCOhost/ INDEX COPERNICUS/ OAJI / DRJI I JOURNAL INDEX / I2OR / SCIENCE LIBRARY INDEX / Google Scholar / Academic Keys / ROAD Open Access I Academic Resources / Scientific Indexing Services / SCIPIOI JIFACTOR

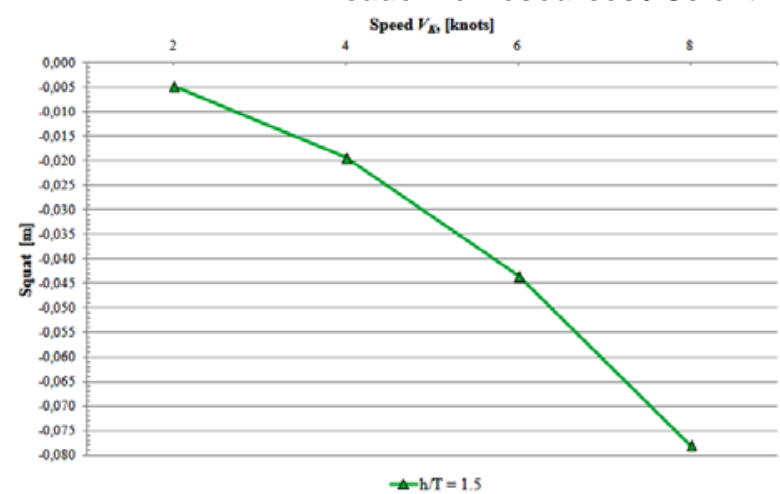

Figure 10. Squat variation at $h / T=1.5$
The results of the study show that ANSYS CFX can be used effectively for the prediction of ship squat in shallow water, but further investigation of hydrodynamic effects in confined waters or canals is required.

\section{CONCLUSIONS}

This paper presents the steps of the CFD numerical simulations made to observe the effects of shallow water on sailing ship MIRCEA hull, such as geometric model construction, mesh generation, mathematical model definition and results interpretation. The hull was geometrically shaped up to $7 \mathrm{~m}$ draft, after which a fluid domain with a depth of $1.5 \cdot T$ was defined.

The mathematical model used in numerical simulations uses Reynolds averages Navier-Stokes equations (RANSE) to solve the problem. After studying the literature, it was concluded that of all the twoequation isotropic turbulence models currently available, the $k-\omega S S T$ is the most advanced and applicable to ship hydrodynamic simulations.

Based on the results analysis, it has been observed that the velocity variation obtained in the fluid domain along the hull has a normal distribution with a potential increase in the flow rate under the hull due to the interaction between the ship's body and the bottom of the domain. Also, the pressure variation on hull is in accordance with the theoretical notions of a ship's pressure domain, with two positive pressure bulbs at forward and aft, and one negative pressure zone at the bottom along the hull. When increasing the speed, the vertical hydrodynamic force decreases with higher negative values, indicating a strong interaction between the hull and the bottom of the domain.

It has been observed that squat variation is dependent on depth and speed and the values obtained from the CFD simulations are in the order of centimetres, values correspondent to ship dimensions and considered speeds.

Determination of navigation problems in shallow water is important, especially the determination of its influence on ship draft and ship resistance. These simulations are necessary for the development and optimization of hull shapes, dimensional ratios or fineness coefficients, without using tests on scale models in towing tanks that prove to be costly and time consuming

\section{BIBLIOGRAPHY}

[1] P. Benes and R. Kollarik, "Preliminary Computational Fluid Dynamics (CFD) Simulation of Ellb Push Barge in Shallow Water", in Scientific Proceedings 2011, Faculty of Mechanical Engineering, STU in Bratislava, vol. 19, 2011, pp. 67-73.

[2] V. Bertram, Practical Ship Hydrodynamics, $2^{\text {nd }}$ ed., Ed. Elsevier, Oxford, 2012.

[3] M. Ristea, A. Popa and A. Cotorcea, "RANSE Simulation for a Two DoF Ship Model", in "Mircea cel Bătrân" Naval Academy Scientific Bulletin, vol. XVIII, issue 2, 2015, pp. 148-152.

[4] M. Ristea, A. Popa and D. Neagu, "CFD Modelling of a 5 Bladed Propeller by Using the RANSE Approach", in "Mircea cel Bătrân" Naval Academy Scientific Bulletin, vol. XVIII, issue 2, 2015, pp. 153-158.

[5] F. Stern et al., "Computational Ship Hydrodynamics: Nowadays and Way Forward", in International Shipbuilding Progress, vol.60, no. 1-4, 2013, pp. 3-105.

[6] $\quad$ P. S. Șerban, "Numerical Simulation of Shallow Waters Effects on Sailing Ship Mircea Hull", in "Mircea cel Bătrân" Naval Academy Scientific Bulletin, vol. XIX, issue 2, 2016, pp. 97-102.

[7] *** Ansys Inc., ANSYS CFX 16.2 manual, 2015. 